\title{
(Dis) integrated valuation - Assessing the information gaps in ecosystem service appraisals for governance support
}

\author{
D.N. Barton ${ }^{\mathrm{a}, *}$, E. Kelemen ${ }^{\mathrm{b}, \mathrm{c}}$, J. Dick ${ }^{\mathrm{d}}$, B. Martin-Lopez ${ }^{\mathrm{e}}$, E. Gómez-Baggethun ${ }^{\text {a,f }}$, S. Jacobs ${ }^{\mathrm{g}}$, \\ C.M.A. Hendriks ${ }^{\text {h }}$, M. Termansen ${ }^{i}$, M. García- Llorente ${ }^{j}$, E. Primmer ${ }^{k}$, R. Dunford ${ }^{1, m}$, P.A. Harrison ${ }^{\mathrm{d}}$, \\ F. Turkelboom ${ }^{\mathrm{g}}$, H. Saarikoski ${ }^{\mathrm{k}}$, J. van Dijk ${ }^{\mathrm{n}}$, G.M. Rusch ${ }^{\mathrm{o}}$, I. Palomo ${ }^{\mathrm{o}}$, V.J. Yli-Pelkonen ${ }^{\mathrm{p}}$, L. Carvalho ${ }^{\mathrm{d}}$, \\ F. Baró ${ }^{\mathrm{q}}$, J. Langemeyer ${ }^{\mathrm{r}}$, J. Tjalling van der Wal ${ }^{\mathrm{d}}$, P. Mederly ${ }^{\mathrm{s}}$, J.A. Priess ${ }^{\mathrm{t}}$, S. Luque ${ }^{\mathrm{u}}$, P. Berry ${ }^{\mathrm{v}}$, R. Santos ${ }^{\mathrm{v}}$, \\ D. Odee ${ }^{\mathrm{c}, \mathrm{w}}$, G. Martines Pastur ${ }^{\mathrm{x}}$, G. García Blanco ${ }^{\mathrm{y}}$, S-R. Saarela ${ }^{\mathrm{k}}$, D. Silaghi ${ }^{\mathrm{z}}$, G. Pataki ${ }^{\text {aa }}$, F. Masi $^{\text {ab }}$, \\ A. Vădineanu ${ }^{\text {ac }}$, R. Mukhopadhyay ${ }^{\text {ad }}$, D.M. Lapola ${ }^{\text {ae }}$
}

a Institute for Nature Research (NINA), Gaustadalléen 21, 0349 Oslo, Norway

${ }^{\mathrm{b}}$ Environmental Social Science Research Group (ESSRG Ltd.), Rómer Flóris u.38, 1024 Budapest, Hungary

${ }^{\mathrm{c}}$ Department of Decision Sciences, Corvinus University of Budapest, Fövám tér 8, 1093 Budapest, Hungary

${ }^{\mathrm{d}}$ Centre for Ecology and Hydrology, Bush Estate, Penicuik, Midlothian EH26 OQB, UK

${ }^{\mathrm{e}}$ Leuphana University of Lüneburg, Faculty of Sustainability, Institute of Ethics and Transdisciplinary Sustainability Research, Scharnhorststraße 1, 21355 Lüneburg, Germany

${ }^{\mathrm{f}}$ Department of International Environment and Development Studies (Noragric), Norwegian University of Life Sciences (NMBU), P.O. Box 5003, N-1432 Ås, Norway

${ }^{\mathrm{g}}$ Research Group Nature and Society, Research Institute for Nature and Forest (INBO), Kliniekstraat 25, 1070 Brussels, Belgium

${ }^{\mathrm{h}}$ Wageningen University and Research, Environmental Research (Alterra), P.O. Box 47, 6700 AA Wageningen, The Netherlands

${ }^{\mathrm{i}}$ ENVS, Aarhus University, Denmark

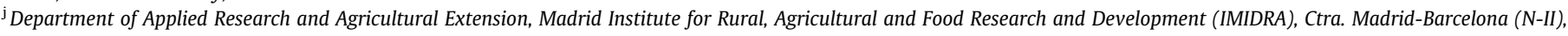
KM. 38.200, 28802 Alcalá de Henares, Madrid, Spain

${ }^{\mathrm{k}}$ Finnish Environment Institute, P.O. Box 140, FI-00251 Helsinki, Finland

${ }^{1}$ Environmental Change Institute, Dyson Perrins Building, South Parks Road, Oxford OX1 3QY, UK

${ }^{\mathrm{m}}$ Centre for Ecology \& Hydrology Maclean Building, Benson Lane, Crowmarsh Gifford, Wallingford, Oxfordshire OX10 8BB, UK

${ }^{\mathrm{n}}$ Norwegian Institute for Nature Research (NINA), Postboks 5685 Torgarden, 7485 Trondheim, Norway

${ }^{\circ}$ Basque Centre for Climate Change (BC3), Sede Building 1, 1st Floor, Scientific Campus of the University of the Basque Country, 48940 Leioa, Spain

${ }^{\mathrm{P}}$ Department of Environmental Sciences, P.O. Box 65, FI-00014 University of Helsinki, Finland

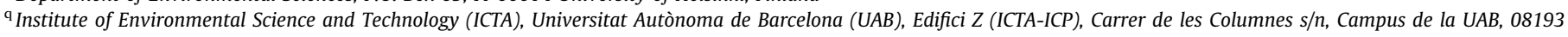
Cerdanyola del Vallès, Barcelona, Spain

${ }^{\mathrm{r}}$ Wageningen University and Research, Marine Research (IMARES), P.O. Box 57, 1780 AB, Den Helder, Wageningen, The Netherlands

${ }^{\mathrm{s}}$ Department of Ecology and Environmental Sciences, Constantine the Philosopher University in Nitra, Tr. A. Hlinku 1, 94901 Nitra, Slovakia

${ }^{\mathrm{t}}$ Helmholtz-Centre for Environmental Research - UFZ, Permoserstraße 15, 04318 Leipzig, Germany

${ }^{\mathrm{u}}$ National Research Institute of Science and Technology for Environment and Agriculture, IRSTEA, UMR TETIS, 500 rUe JF BRETON, Montpellier 34000 CEDEX 5, France

${ }^{v}$ CENSE - Centre for Environmental and Sustainability Research, Faculdade de Ciências e Tecnologia, Universidade Nova de Lisboa, 2829-516 Caparica, Portugal

${ }^{\mathrm{w}}$ Kenya Forestry Research Institute (KEFRI), P.O. Box 20412-0200, Nairobi, Kenya

${ }^{x}$ Centro Austral de Investigaciones Científicas (CADIC CONICET), Houssay 200, Ushuaia (9140) Tierra del Fuego, Argentina

${ }^{\text {y } F u n d a c i o ́ n ~ T e c n a l i a ~ R e s e a r c h ~ E ~ I n n o v a t i o n, ~ E n e r g y ~ a n d ~ E n v i r o n m e n t ~ D i v i s i o n, ~ P a r q u e ~ T e c n o l o ́ g i c o ~ d e ~ B i z k a i a, ~ C / G e l d o, ~ E d i f i c i o ~ 700, ~ E-48160 ~ D e r i o, ~ B i z k a i a, ~ S p a i n ~}$

${ }^{\mathrm{z}}$ National Institute for Research and Development in Forestry "Marin Dracea", Eroilor Blvd 128, Voluntari, Romania

${ }^{\text {aa }}$ Institute of Ecology and Botany, MTA Centre for Ecological Research, Alkotmány u. 2-4., 2163 Vácrátót, Hungary

ab IRIDRA Srl, Via La Marmora, 51., 50121 Florence, Italy

ac University of Bucharest - Research Center in Systems Ecology and Sustainability, Splaiul Independentei 91-95, 050095 Bucharest, Romania

${ }^{\text {ad }}$ IBRAD (Indian Institute of Bio Social Research and Development), VIP Road, Kestopur, Prafulla Kanan, Kolkata 700101, West Bengal, India

${ }^{\text {ae } U N E S P ~-~ U n i v e r s i d a d e ~ E s t a d u a l ~ P a u l i s t a, ~ E c o l o g y ~ D e p a r t m e n t ~-~ L a b T e r r a, ~ A v .24-A, ~} 1515$ CEP: 13506-900, Rio Claro, São Paulo, Brazil

\section{A R T I C L E I N F O}

\section{Article history:}

Received 15 January 2017

Received in revised form 22 October 2017

Accepted 27 October 2017

Available online 15 December 2017

\begin{abstract}
A B S T R A C T
The operational challenges of integrated ecosystem service (ES) appraisals are determined by study purpose, system complexity and uncertainty, decision-makers' requirements for reliability and accuracy of methods, and approaches to stakeholder-science interaction in different decision contexts. To explore these factors we defined an information gap hypothesis, based on a theory of cumulative uncertainty in ES appraisals. When decision context requirements for accuracy and reliability increase, and the expected uncertainty of the ES appraisal methods also increases, the likelihood of methods being used
\end{abstract}

\footnotetext{
* Corresponding author.

E-mail address: david.barton@nina.no (D.N. Barton).
} 


\section{Keywords:}

Integrated valuation

Ecosystem service appraisal

Ecosystem service governance

Information costs

Uncertainty

Valuation

Eccosystem services cascade is expected to drop, creating a potential information gap in governance. In order to test this information gap hypothesis, we evaluate 26 case studies and 80 ecosystem services appraisals in a large integrated EU research project. We find some support for a decreasing likelihood of ES appraisal methods coinciding with increasing accuracy and reliability requirements of the decision-support context, and with increasing uncertainty. We do not find that information costs are the explanation for this information gap, but rather that the research project interacted mostly with stakeholders outside the most decision-relevant contexts. The paper discusses how alternative definitions of integrated valuation can lead to different interpretations of decision-support information, and different governance approaches to dealing with uncertainty.

(c) 2017 Elsevier B.V. All rights reserved.

\section{Introduction}

Ecosystem service (ES) appraisal methods include biophysical mapping, modelling, socio-cultural and economic assessments. Recent reviews point to a persistent gap in the promise of ES appraisal methods to provide readily usable information for decision-support (Laurans et al., 2013; Ruckelshaus et al., 2015; Martinez-Harms et al., 2015). The challenge is broader than lacking operationalisation of monetary valuation in decision-making (TEEB, 2010). Valuation in its broad sense of 'assigning importance' is inherently part of decisions on natural resource and land use (Gómez-Baggethun et al., 2014). The literature reviews testify to a general pattern of 'disintegrated valuation', both in terms of integration of appraisals across the ES cascade (Haines-Young and Potschin, 2010), and operational application of ES appraisals in governance (Primmer et al., 2015; Verburg et al., 2016).

There are recent examples of integrated valuation across multiple types of value which are exceptions to the broad patterns revealed by literature reviews cited above, e.g. (Fontaine et al., 2014; Martin-Lopez et al., 2014; IPBES, 2015; van Oudenhoven et al., 2015; Yee et al., 2015; Barton et al., 2016; Grêt-Regamey et al., 2016). However, gaps in the operationalisation of ES appraisal for governance support remain. Martinez-Harms et al. (2015) review 144 studies, and find that ecosystem service appraisals do not capture the core steps of the decision making process, with much of the literature focused on quantifying and mapping the supply of ecosystem services. A review by Laurans et al. (2013) shows that a majority of studies have been conducted for informative uses, and only $2 \%$ of the 313 studies reviewed have targeted decision-making. Among the reasons explaining the lack of valuation applications in policy, Laurans et al. (2013) suggest data inaccuracy, information costs, lack of expertise among decisionmakers, and lack of compatibility between valuation methods and regulatory frameworks.

Based on empirical case study experiences in the Natural Capital Project, Ruckelshaus et al. (2015) define four impact pathways for ES appraisal: (i) conducting research that is disseminated, (ii) making stakeholder differences transparent, and mediating through changing their perspectives, (iii) generating action in new policy and finance mechanisms, and (iv) producing outcomes for biodiversity, ecosystem services and well-being. Their impact pathways highlight that ES appraisals can have multiple and iterative purposes ranging from explorative research for systems understanding, to supporting design of policy instruments and documenting their outcomes. While most studies in the Natural Capital project addressed the first three purposes to some degree, only one of 22 case studies had documented outcomes during the six years of the project. Ruckelshaus et al. (2015) argue that this is to be expected, given the time taken to conduct studies and the significant time lags between multi-sector planning processes involved in ecosystem management and measurable impact on the ground.
A broad research community is working to conceptualise the multiple values of nature and nature's contributions to people, beyond monetary valuation (IPBES, 2015; Pascual, 2017; Jacobs, 2018). Similarly to the efforts to mainstream the economics of nature (TEEB, 2010), efforts are also under way to operationalize plural values in decision-making. For example in a recent special issue $^{1}$, Jacobs et al. (2016) call for a 'new school of integrated valuation', which would address multiple values, through self-critical reflexive research, learning from real world applications and aiming at societal, rather than only academic impact. They call for research that understands the socio-political setting of decision-making mechanisms and provides instrumental criteria of credibility and legitimacy that can help determine the appropriate level of integration.

The aim of this paper is to evaluate the practical challenges of integrated ES appraisals, in particular how study purpose, uncertainty, stakeholder requirements for reliability and accuracy, and stakeholder-science interaction co-determine the uptake and influence of integrated ES appraisal methods in different decision contexts. We analyse a diverse set of real-world case studies of the EU FP7 OpenNESS project (Dick et al., 2018), which have operationalised the ES concept and applied a range of biophysical, socio-cultural and monetary ES appraisal methods, as well as 'hybrid' and 'integrating' methods (Gómez-Baggethun et al., 2014). Through this analysis, we report on the extent to which the project as a whole succeeded in narrowing the gap between ES appraisal and governance support - or how far we came in putting the parentheses in '(dis)integrated valuation'.

\section{A theory of cumulative uncertainty in integrated ES appraisal}

The accuracy and reliability required of ES appraisal methods must be seen in the context of the socio-ecological system in which it is applied. Uncertainty in ES appraisals results from the number of perspectives and values to be considered, the extent and complexity of the social system and ecosystems that are being appraised. Integrated ES appraisal for decision-support faces a challenge of addressing uncertainty from biophysical, sociocultural and value heterogeneity (Gómez-Baggethun et al., 2014). Integrated environmental modelling shows us that methodological and measurement errors across conditionally dependent models is cumulative (Barton et al., 2016). Conditionally dependent appraisal methods can be expected to accumulate uncertainty across sequentially linked models, especially if model parameters are not estimated jointly across models. Clearly, this will further challenge application of integrated valuation in governance. Those governance mechanisms that address the entire ES cascade - hierarchical governance in particular - would require comprehensive

\footnotetext{
1 See special issue on Integrated valuation of ecosystem services: challenges and solutions Ecosystem Services, Volume 22, Part B, Pages 213-402 (December 2016) http://www.sciencedirect.com/science/journal/22120416/22/part/PB.
} 
appraisal (Primmer et al., 2015). Paradoxically, comprehensive appraisals that document uncertainty might not seem appealing for operational use in governance support if they uncover large uncertainty about system response to policy (Barton et al., 2008). Here we argue that cumulative uncertainty is one reason we would expect to find few valuation studies integrated in decision-support appraisals, as documented by Laurans et al. (2013) and MartinezHarms et al. (2015).

Fig. 1 outlines a theory of cumulative uncertainty in an integrated chain of ES appraisal methods. It builds on the ES cascade framework (Haines-Young and Potschin, 2010) which suggests a sequential cascade of linked ecosystem appraisals, leading to final valuation outcomes. In the original ES cascade framework valuation outcomes feed back to policy actions that control pressures. The ES cascade framework has been criticized and further developed in ways that provide support for a cumulative theory of uncertainty in integrated ES appraisal (Spangenberg et al., 2014; Nassl and Loffler, 2015; Primmer et al., 2015; Potschin and Haines-Young, 2016; Hausknost et al., 2017). Spangenberg et al. (2014) propose that different kinds of agency are required to trans- form biophysical structures and processes into ecosystem service values, including use value attribution, mobilisation of ecosystem service potentials into ecosystem services, appropriation of ecosystem services as benefits of use, and commercialisation of use values into exchange values. The transformation and maintenance of nature for societally desired states as depicted by Spangenberg et al. (2014) requires a constant input of energy (Hausknost et al., 2017). Hausknost et al. (2017) suggest that the ES cascade be depicted as a 'stairway' metaphor where each step in appraisal or appropriation requires the investment of human agency, involving work, time and other resources. ES appraisal involves the investment of human agency in the production of information to reduce uncertainty (entropy) about states of nature resulting from actions to transform and maintain it for societal purposes.

Nassl and Loffler (2015) discuss the ecosystem service cascade as an integrated environmental assessment framework, drawing parallels to the driver-pressure-state-impact-response (DPSIR) framework. ES appraisal to support decisions requires some form of integration across such a DPSIR chain, including (i) identification of changes in values, subject to (ii) change in ecosystem services,

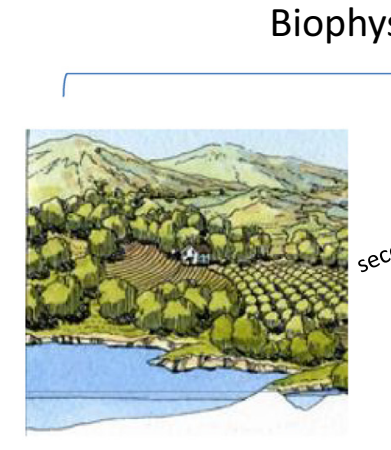

Biophysical heterogeneity

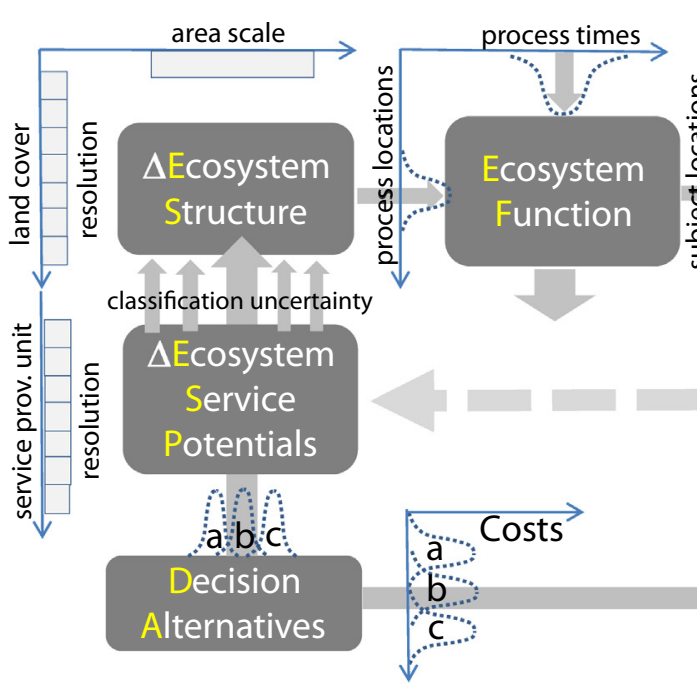

\section{Socio-cultural heterogeneity}
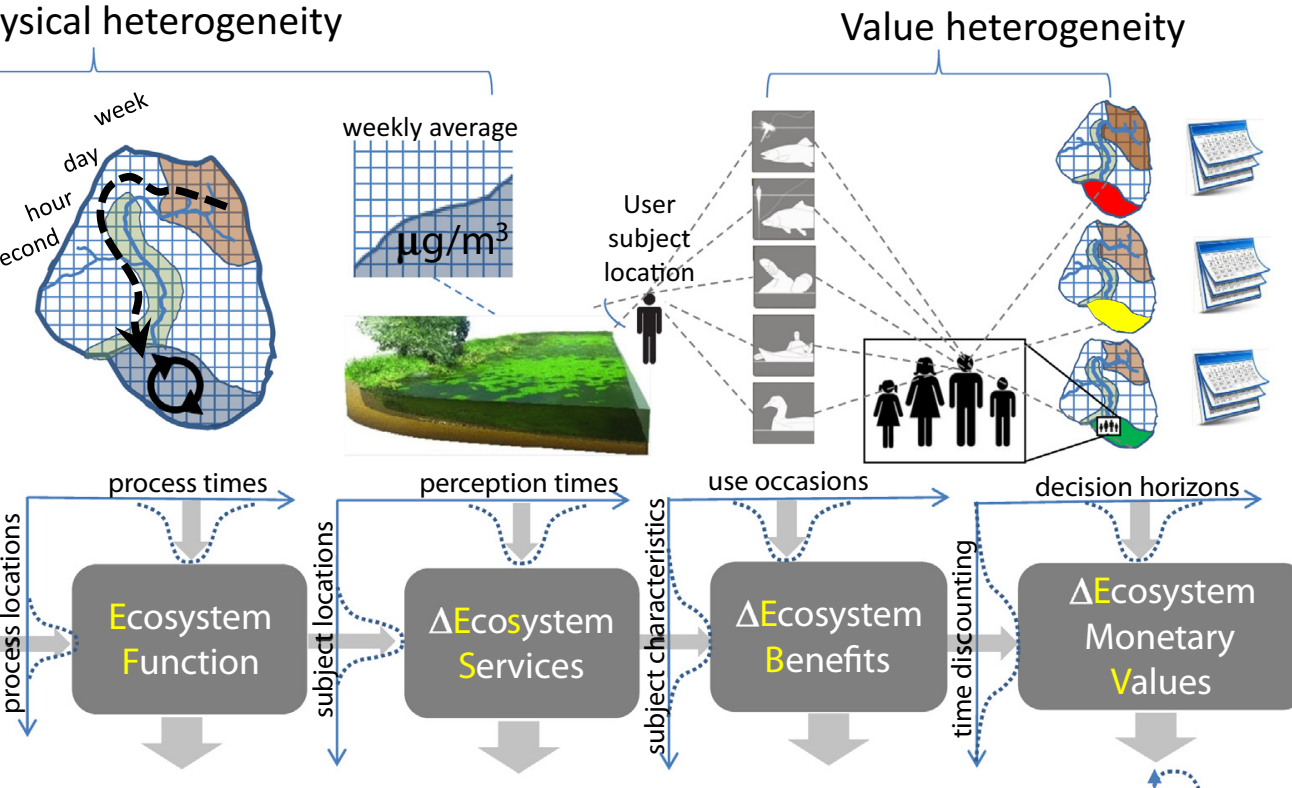

decision horizons

a posteriori updating of expectations
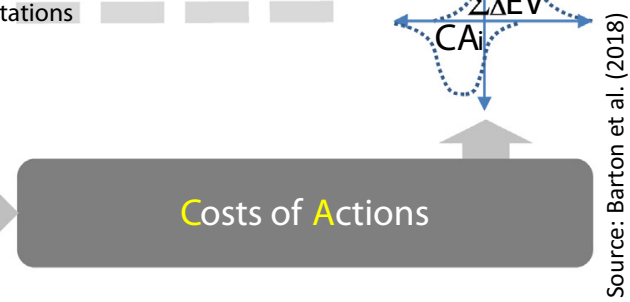

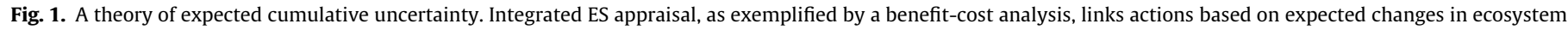

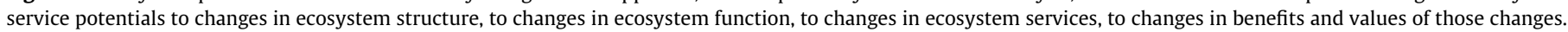

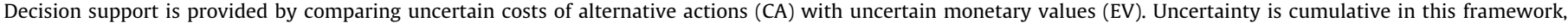

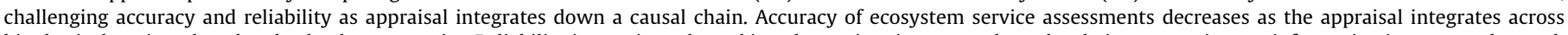

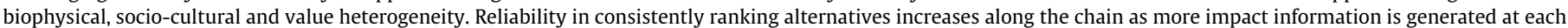

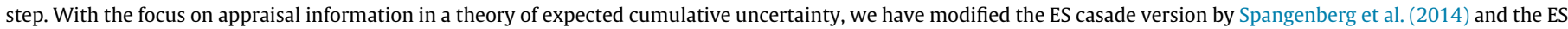

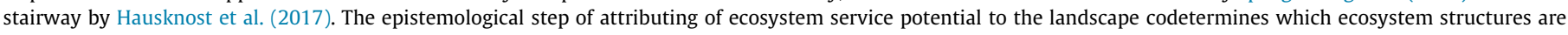

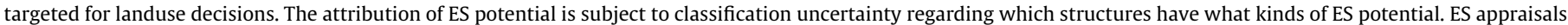

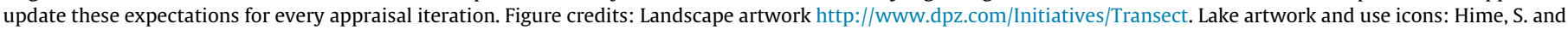
I.J. Bateman, A transferable water quality ladder for conveying use and ecological information within public surveys, CSERGE, University of East Anglia. 2008. 
subject to (iii) change in ecosystem condition, subject to (iv) identification of ecosystem service potential associated with (v) the ecosystem structures in question.

A theory of cumulative uncertainty proposes that integrated ES appraisal as defined in Fig. 1 is subject to cumulative uncertainty in its outcomes. Cumulative uncertainty can be actual, as when a series of models are linked to simulate impacts of management decisions (Barton et al., 2016). Cumulative uncertainty can also be expected, as when decision-makers are already familiar with the complexity of the system they are managing. Rational decision-makers will assess how accurately and reliably study outcomes are linked to the decision alternatives at hand. While an ES appraisal may not have conducted sensitivity analysis or probability simulation, rational decision-makers will formulate expectations about how uncertain outcomes are, relative to the purpose of interest to them. Their expectations will be based jointly on the complexity of the context, and the complexity of assumptions of the ES appraisal method. Primmer et al. (2015) discuss how different governance mechanisms have arisen to address uncertainty and different information inputs along the ES cascade. Hierarchical, scientific-technical, adaptivecollaborative and strategic governance rest on different information assumptions, and use information in differing ways to reduce uncertainty for different governance purposes (Primmer et al., 2015).

Gómez-Baggethun and Barton (2013) identified a range of governance purposes of urban ES valuation (Fig. 2), including (i) awareness-raising, (ii) accounting, (iii) priority-setting, (iv) instru- ment design, and (v) litigation. Schröter et al. (2014) proposed a similar ordering of study purposes in the context of ecosystem accounting at regional and national scales. They argued that different purposes can be organised along a gradient of increasing decision-maker expectations for accuracy and reliability. The more accuracy and reliability required of the purpose of the analysis, the more tailored and information intensive ES appraisal methods need to be.

Accuracy and reliability of different ES appraisal methods are key concerns for practitioners (Dick et al., 2018; Dunford et al., 2018; Harrison et al., 2018). Literature reviews highlight information costs as one of several challenges to operationalisation of the ecosystem services concept (Bagstad et al., 2013; Laurans et al., 2013; Ruckelshaus et al., 2015). Bagstad et al. (2013) argue that the time and resources needed to obtain data, analyse and communicate results constitute one of the most important challenges. The fact that ecosystem service appraisals are costly is trivial. The point we wish to make is that information costs increase incrementally with both system complexity and decision-support purpose. Further, decision-makers' requirements for accuracy and reliability will be correlated with increasing information costs if, and only if, ES appraisers make efforts to meet those requirements (Gómez-Baggethun and Barton, 2013). In other words, both decision-makers and ES appraisers need to have a common terminology for ES appraisal uncertainty and decision-purpose to avoid a gap in expectations. To this end we formulate an information gap hypothesis and show how it can be used to compare across ES appraisal methods and their purposes in practice.

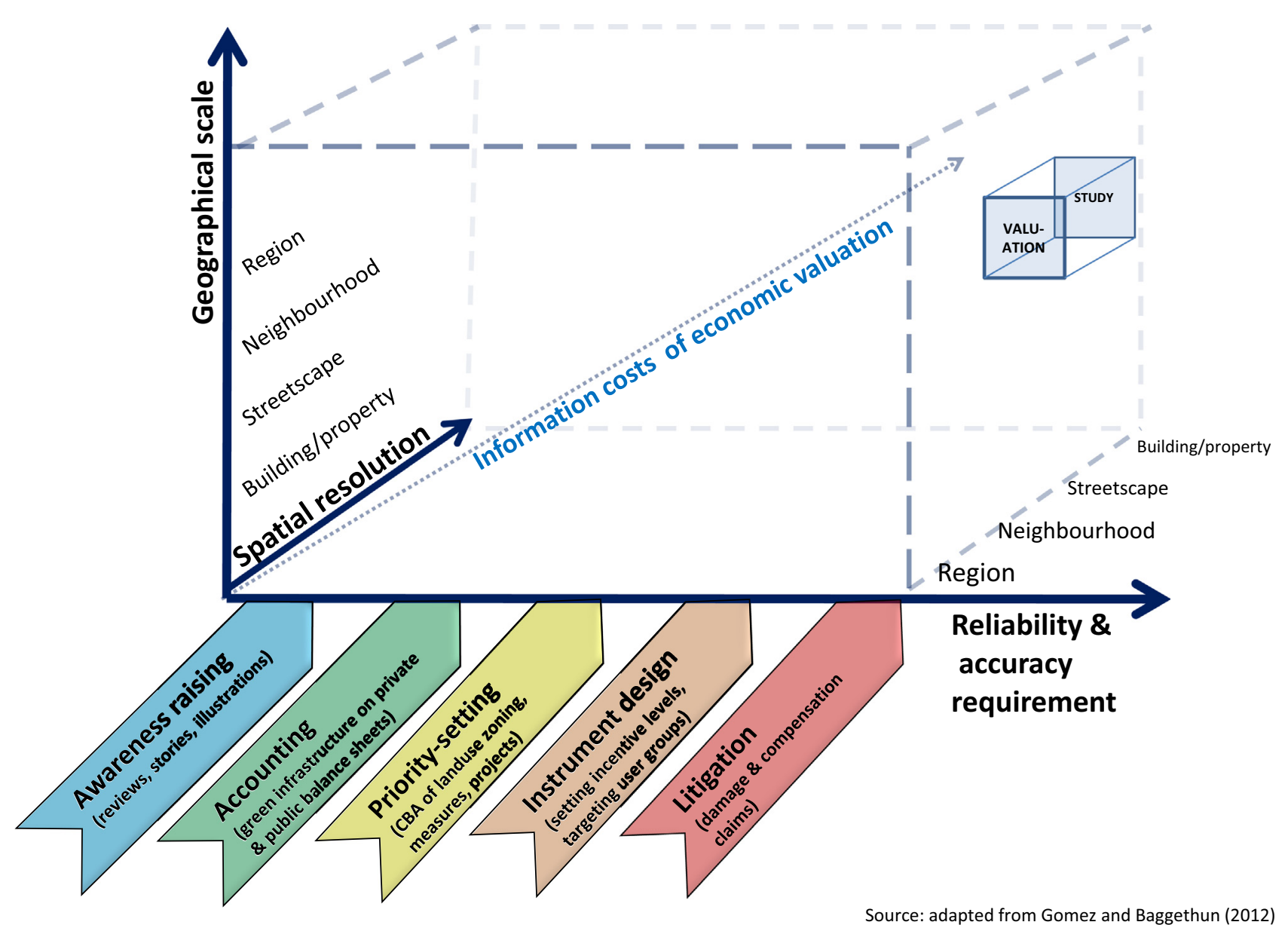

Fig. 2. A framework for decision contexts for economic valuation of ecosystem services. Source: Gómez-Baggethun and Barton (2013). 


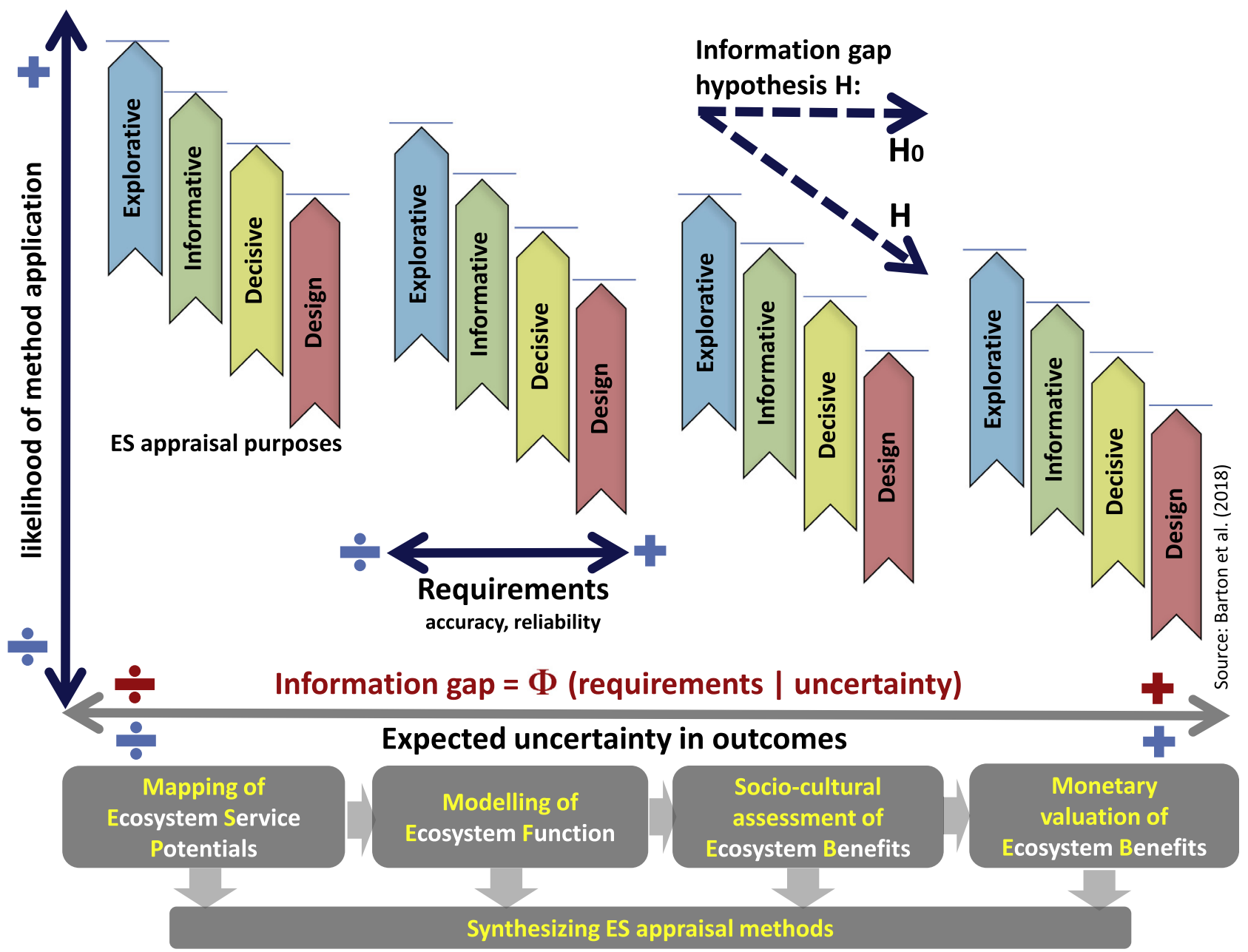

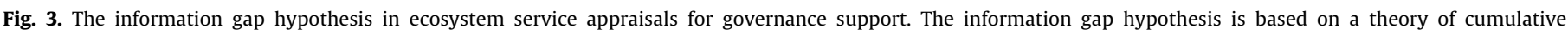

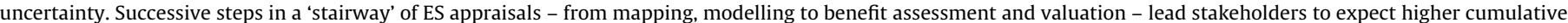

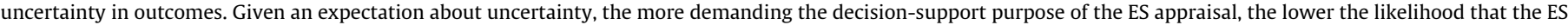

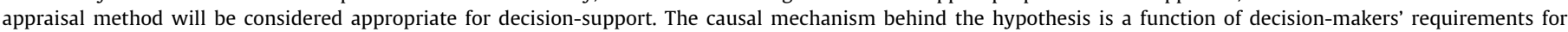

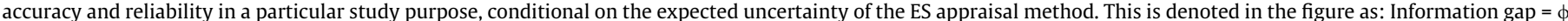

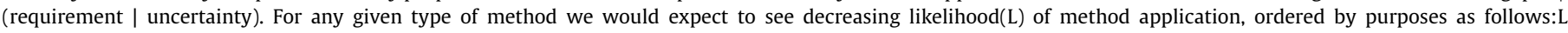

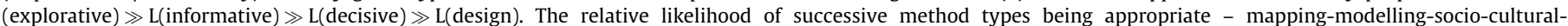

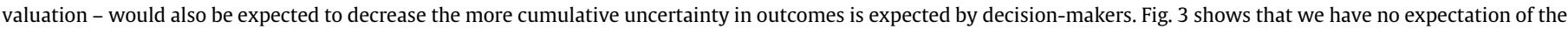

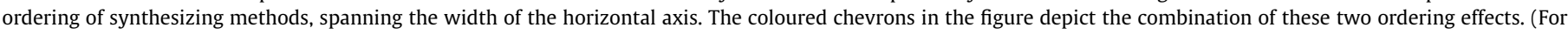
interpretation of the references to colour in this figure legend, the reader is referred to the web version of this article.)

\section{The information gap hypothesis}

The information gap hypothesis is based on two propositions, the first regarding the expected uncertainty of appraisal methods and the second regarding decision-makers' requirements (Fig. 3).

\subsection{Expected uncertainty in outcomes}

The theory of cumulative uncertainty in ES appraisal (Fig. 1) proposes a classification of ES appraisal methods along the ES stairway in order of increasing expected uncertainty in outcomes. Expected uncertainty increases with the position of the method in the appraisal chain. The further along the appraisal chain the lower its likelihood of application assuming decision-makers avoid appraisal uncertainty. The information gap hypothesis therefore predicts an ordering of methods' likelihood of application as follows. (1) ES mapping methods aimed at attributing ecosystem service potentials. (2) ES modelling methods aimed at describing the response function between changes in structure and services. (3)
Socio-cultural assessments aimed at identifying qualitative ES benefits from use values. (4) Monetary valuation aimed at identifying economic values of ES benefits (see Table 2, next section for examples). While synthesizing methods accumulate uncertainty from multiple methods, their purpose is to compare and triangulate different indicators of importance, thereby reducing overall uncertainty about decision alternatives (Jacobs et al., 2016; Jacobs, 2018). This would lead us to expect some intermediate likelihood of application, as the effects of entropy in complexity and information through triangulation are balanced against oneanother.

\subsection{Decision-makers' requirements}

The typology of decision purposes and their requirements is based on previous reviews (Gómez-Baggethun and Barton, 2013; Laurans et al., 2013; Martinez-Harms et al., 2015; Ruckelshaus et al., 2015). Four broad typologies of ES appraisal purpose are defined, including explorative, informative, decisive and design purposes (see Table 1 for definitions). The requirements for accuracy and reliability increase systematically across these four broad 
Table 1

Range of study purposes of each ES appraisal method scored by case study representatives.

\begin{tabular}{ll} 
Explorative & $\begin{array}{l}\text { Conduct research aimed at developing science and changing } \\
\text { Understanding of research peers }\end{array}$ \\
E1 & Theory and concept development \\
E2 & Hypothesis formulation and testing \\
E3 & Method development and testing \\
Informative & Change perspectives of public \& stakeholders \\
I1 & Assessment of current state \\
I2 & Assessment of long-term historic trends \\
I3 & Assessment of potential future conditions \\
I4 & Evaluation of existing projects and policies \\
I5 & Raising awareness of the importance of ES \\
I6 & Raising awareness of trade-offs and conflicts between ES \\
Decisive & Generate action in specific decision problems by stakeholders \\
D1 & Decision problem formulation and structuring \\
D2 & Criteria for screening alternatives \\
D3 & Criteria for ranking alternatives \\
D4 & Criteria for spatial targeting (zoning \& planning of alternatives) \\
D5 & Arguments for negotiation, shared norms \& conflict resolution \\
Design & Produce outcomes through design and implementation of \\
& policy instruments with stakeholders \\
T1 & Standards \& policy target-setting \\
T2 & Land and natural resource management rules \& regulations \\
T3 & Licencing / permitting / certification \\
T4 & Pricing, setting incentive levels \\
T5 & Establishing levels of damage compensation \\
\hline
\end{tabular}

study purposes, following the rationale in Fig. 2. Explorative purposes rely on research agenda driven analyses, with low expectations for direct application to decision-making, generating few costs for governance support. Informative purposes include awareness raising about importances of ecosystem services, with no specification of decision context. Decisive purposes require ES appraisal to distinguish between the desirability of alternative decisions. Design purposes have the highest requirements for accuracy and reliability, as values are used to calibrate the scope and targeting of policy instruments and management actions.

Combining these two propositions, the information gap hypothesis states that the more demanding the decision-support purpose of the ES appraisal, the lower the likelihood that the ES appraisal will be considered appropriate for decision-support, conditional on an expected uncertainty defined by system and method complexity. Decreasing likelihood of the method being appropriate indicates an information gap in ES appraisal for governance support (Fig. 3). The information gap may result whether researchers identify the uncertainty of their methods or not - it relies crucially on decision-makers expectations.

The information gap hypothesis is based on a theory of cumulative uncertainty and a classification and ordering of method and their purposes, either of which may be disproved. The information gap hypothesis could be rejected $\left(H_{0}\right)$ by limitations in the classifications of methods, purposes and the requirements assumed to order them. For example, explorative research purposes may have high accuracy requirements if testing and developing theories that make precise predictions. Large data sets with high information costs may be needed to obtain sufficient statistical power - the likelihood of observing methods applied for explorative purposes might in such cases be low, rather than high as predicted by the information gap hypothesis. At the other end of the scale it could be argued that technical design may be understood as repetitive and requiring little accuracy and reliability. In that case, low information costs would lead us to expect a high likelihood of methods being applied for design purposes. Furthermore, individual methods may be misclassified in terms of the method type they are assumed to belong to (Table 2, Supplementary Material S2). If such misclassification is significant, the information gap hypothesis $(H)$ in Fig. 3 would also be rejected. We would see no ordering as in $H_{0}$, or even increasing likelihood of methods with increasing uncertainty and requirements.

As explained above, we expect constraints on data, budget and time available for appraisals supporting governance to be important reasons for the likelihood of method selection decreasing according to the information gap hypothesis. But there may also be alternative explanations for observing 'much mapping and little valuation'. These may include the lack of participation of decisionmandated stakeholders, lack of compatibility between research and operational needs, as well as how risk is managed by different types of governance. These alternative explanations are addressed in the discussion section.

\section{Materials and methods}

The OpenNESS project was designed to operationalise the ecosystem services concept in case studies across Europe, Brazil, Kenya and India, through close collaboration between researchers and stakeholders (Dick et al., 2018). In the last year of the project, 26 case study leaders and 246 stakeholders responded to targeted surveys evaluating the different methods applied during the project period from 2013 to 2016. The survey of case study leaders provided information on the researcher perceived purpose of studies and operational constraints. The stakeholder survey provided information on stakeholders perceived interaction with the appraisal methods.

\subsection{Case study leader survey}

A survey was circulated to case study research teams in 2016, in which the case study leaders were asked to identify all the appraisal methods used within their case study. For each appraisal method, the respondents were asked to score considerations that influenced their decision to use that method within their case study. For the complete survey protocol of case study coordinators, see Dick et al. (2018) Supplementary Material - "Annex 4 Case study context reporting forms part 2". For an analysis of a comprehensive evaluation of case study considerations see

Table 2

Classification of ES appraisal methods used by case studies.

\begin{tabular}{|c|c|c|c|c|}
\hline Mapping $(n=24)$ & $\begin{array}{l}\text { Biophysical Modelling } \\
(n=10)\end{array}$ & $\begin{array}{l}\text { Socio-cultural valuation } \\
(n=25)\end{array}$ & $\begin{array}{l}\text { Monetary valuation } \\
(n=12)\end{array}$ & $\begin{array}{l}\text { Synthesising methods } \\
(n=9)\end{array}$ \\
\hline $\begin{array}{l}\text { - ESTIMAP } \\
\text { - Matrix approach } \\
\text { - Quickscan } \\
\text { - Smarthphone Apps } \\
\text { - PPGIS }\end{array}$ & $\begin{array}{l}\text { - SITE Landuse model } \\
\text { - Bayesian belief network } \\
\text { - Climate envelope modelling } \\
\text { - Hydrological model } \\
\text { - Meta-analysis }\end{array}$ & $\begin{array}{l}\text { - Questionnaire \& narrative analysis } \\
\text { - Photoseries analysis } \\
\text { - Preference assessment } \\
\text { - Time use } \\
\text { - Q-method } \\
\text { - Deliberative valuation } \\
\text { - Stakeholder analysis } \\
\text { - Focus group }\end{array}$ & $\begin{array}{l}\text { - Time use value } \\
\text { - Value transfer } \\
\text { - Cost-based } \\
\text { - Revealed preference } \\
\text { - Stated preference }\end{array}$ & $\begin{array}{l}\text { - Integrated mapping-modelling } \\
\text { (INVEST, EcoServ) } \\
\text { - Scenario development } \\
\text { - Multi-criteria decision analysis } \\
\text { - Benefit-cost analysis }\end{array}$ \\
\hline
\end{tabular}


Dunford et al. (2018). In this paper we focus on the subset of considerations concerning study purposes and information constraints. Table 1 describes 19 different study purposes in ES assessment, based on a synthesis of decision contexts and impact pathways in the literature (Gómez-Baggethun and Barton, 2013; Laurans et al., 2013; Martinez-Harms et al., 2015; Ruckelshaus et al., 2015), adapted to the OpenNESS 26 case studies included in this study.

Study purposes were classified into broad categories including explorative, informative, decisive and technical design in order to test the information gap hypothesis in Fig. 2. A total of 80 ES appraisals in the OpenNESS project were ordered into 5 method types (Table 2) following the framework in Fig. 1. Method descriptions are provided in Supplementary material S2. Most case studies applied more than one method. The survey evaluated case studies' reasons for selecting methods across a large number of criteria (Dunford et al., 2018). Integrated mapping-modelling methods and decision-support methods were grouped together in a single class of "synthesising" methods.

In a research project such as OpenNESS we do not observe the actual frequency of method applications to different purposes, given the limited timespan of the project (Ruckelshaus et al., 2015). Instead we use a proxy indicator of the likelihood of methods application - for each method 26 case study leaders were asked 'To what extent is the way that you use the method in your case study described by the purposes listed (in Table 1)'? (scores: $0=$ "not relevance"; 1 = "relevant" 2 = "primary purpose"). This question provided the indicator of how well a method addressed the explorative, informative, decisive or technical design purposes listed in Table 1. All methods were scored for all 18 purposes in Table 1. A single method could have multiple purposes. Regarding considerations for method selection, case study leaders were asked, 'To what extent are the following practical/researchrelated considerations factors that influenced your choice of this method?' (scores: 0 = "not at all"; 1 = "to some extent" 2 = "very much"). From the list of considerations we used the answers regarding data, budget and time constraints as proxy indicators for information $\operatorname{cost}^{2}$.

\subsection{Case study stakeholder survey}

After three years of OpenNESS case study work in close consultation with case study advisory boards (CAB), a standard questionnaire was administered to 246 case study stakeholders in 2016. For the complete survey protocol of stakeholders, see Dick et al. (2018) with Supplementary Material - "Annex 1 Practitioner's perspective questionnaire". Three methods were used for selecting respondents: (i) restricting the respondents to $C A B$ members ( 8 case studies), (ii) complementing the $\mathrm{CAB}$ respondent group with stakeholders outside the CAB (8 case studies), and (iii) including all stakeholders with relevant involvement in the process, as evaluated by the CAB and case study leader (11 case studies). Given the flexibility and variation across case studies in stakeholder participation during the three years of case study, the importance of $\mathrm{CAB}$ membership was assessed in relative terms. For the OpenNESS project as a whole, stakeholders self-reported their 'membership of the CAB' as follows: very applicable (39\%), applicable (14\%), somewhat applicable (3\%), little bit applicable (6\%) and not applicable (38\%). Partial involvement in the CAB reflects the dynamic nature of $C A B$ membership, with individuals leaving and new members

\footnotetext{
${ }^{2}$ We also applied a survey to case study leaders to quantify person months and expenses allocated per appraisal method. Application of multiple methods per case study meant that several case studies were unable to assign costs exactly. Due to missing responses we reverted to use of the qualitative question described above which was responded to by all but one case study.
}

joining during the lifetime of the project in some case studies (Dick et al., 2018).

The stakeholder questionnaire was structured into four main topics (i) self-characterisation of stakeholders, (ii) perception of the participatory process followed in the case study, (iii) perceived impact, and (iv) practical usefulness of appraisal methods, allowing the stakeholders to feed back their experiences anonymously. We use a selection of the stakeholder survey data for our analysis in particular, the stakeholders' degree of participation in the case study advisory board; the extent to which they participated in study design; method selection; knowledge co-production and how informed they were about results. Knowledge co-production was defined as 'attending workshops/meetings and stakeholder engagement activities' (question wording provided in Supplementary Material S3).

\subsection{Testing the information gap hypothesis}

We defined a $t$-test of differences in the mean scores for ordinal scoring of method relevance, comparing pairwise samples of different study purposes. The $T$-test is robust to testing independent samples even under conditions of non-normality (Rasch et al., 2007; Fagerland et al., 2011). Study purposes were ordered by expected information gap as explained in Fig. 3. Using the scores assigned by case study leaders for each method tested in their case studies, we calculated the mean scores of each method class over each class of study purpose (as defined in Tables 2 and 1, respectively).

Given that we were testing whether there was a reduction (as opposed to increase) in the appropriateness of methods compared over pairwise purposes, we use the reported confidence levels of one side of the $t$-test,

$\operatorname{Pr}(\mathrm{T}<\mathrm{t})$, Ho: mean $($ diff $)=0$, Ha: mean $($ diff $)<0$,

Mean(diff) was the difference in mean scores between pairwise consecutive study purpose categories organised in order of increasing information gap, as defined in Table 1 (Explorative Informative(E-I), Informative - Decisive(I-D), Decisive - Technical design(D-T), Informative - Technical Design(I-T)). In other words, the expectation is that mean $(\mathrm{E}-\mathrm{I})<0$, mean $(\mathrm{I}-\mathrm{D})<0$, mean $(\mathrm{D}-\mathrm{T})$ $<0$, and mean $(\mathrm{I}-\mathrm{T})<0$.

If we infer that for example mean(I-D) $<0$ is true, we are confident that the mean score of informative method applications is higher than the mean score of decisive method applications. Table 3 reports different confidence levels of $\operatorname{Pr}(\mathrm{T}<\mathrm{t})$. Three of the method classes had relatively few observations (modelling, monetary valuation, and synthesising methods). For these method classes the power of the $t$-test is lower, and the test is less likely to observe the hypothesised difference in means.

We next contrasted the results of the hypothesis tests with case study leaders' self-reported evaluation of importance of data, time and budget constraints in selecting the methods actually used. These results are reported in Fig. 4. Recalling Laurans et al. (2013), we also evaluated complementary explanations to the information gap hypothesis using stakeholders' selfreported roles in the project, their degree of participation in decision-making, their perceptions of the general impact of the appraisal methods on decision-making, and prior researcherstakeholder collaboration experience. We use a two-way fractional polynomial plot (Stata, 2013) to illustrate (i) whether stakeholders' participation in case study advisory board was correlated with co-design of ES appraisal methods, and (ii) whether the length of time researchers had worked with stakeholders in the case study prior to OpenNESS was correlated with the importance scores for different study purposes (Supplementarr Material Fig. S2). 
Table 3

$T$-test of the difference in the mean of method relevance scores between consecutive study purposes.

\begin{tabular}{|c|c|c|c|c|}
\hline \multicolumn{5}{|c|}{$\operatorname{Pr}(T<t)$ for Ho: mean(diff) $=0$, Ha: mean(diff $)<0$} \\
\hline $\begin{array}{r}\text { Purposes: } \\
\text { Method groups: }\end{array}$ & $\begin{array}{l}\text { Explorative- } \\
\text { Informatve } \\
\text { mean(E-I) }\end{array}$ & $\begin{array}{l}\text { Informative- } \\
\text { Decisive } \\
\text { mean(I-D) }\end{array}$ & $\begin{array}{c}\text { Decisive- } \\
\text { Technical Design } \\
\text { mean(D-T) }\end{array}$ & $\begin{array}{c}\text { Informative- } \\
\text { Technical design } \\
\text { mean (I-T) }\end{array}$ \\
\hline Mapping & $\begin{array}{l}t=-0.9725 \\
\operatorname{Pr}=0.1678\end{array}$ & $\begin{array}{l}t=2.3522 \\
P r=0.9886\end{array}$ & $\begin{array}{c}t=4.0675 \\
\operatorname{Pr}=0.9999\end{array}$ & $\begin{array}{l}t=7.6059 \\
\operatorname{Pr}=1.0000 \\
\end{array}$ \\
\hline Modelling & $\begin{array}{l}\mathrm{t}=1.1971 \\
\operatorname{Pr}=0.8766\end{array}$ & $\begin{array}{l}t=1.4362 \\
\operatorname{Pr}=0.9159\end{array}$ & $\begin{array}{c}t=0.9909 \\
\operatorname{Pr}=0.8326\end{array}$ & $\begin{array}{c}t=3.8562 \\
\operatorname{Pr}=0.9994\end{array}$ \\
\hline Socio-cultural & $\begin{array}{c}t=0.2905 \\
\operatorname{Pr}=0.6136\end{array}$ & $\begin{array}{c}t=0.8008 \\
\operatorname{Pr}=0.7863\end{array}$ & $\begin{array}{c}t=2.5861 \\
\text { Pr }=0.9935\end{array}$ & $\begin{array}{l}t=4.5755 \\
\operatorname{Pr}=1.0000\end{array}$ \\
\hline Monetary & $\begin{array}{c}t=-1.6848 \\
\operatorname{Pr}=0.0531\end{array}$ & $\begin{array}{l}t=1.3250 \\
\operatorname{Pr}=0.9006\end{array}$ & $\begin{array}{c}t=3.3544 \\
\text { Pr }=0.9986\end{array}$ & $\begin{array}{c}t=\quad 6.1671 \\
\operatorname{Pr}=1.0000\end{array}$ \\
\hline Synthesis & $\begin{array}{c}t=-0.9104 \\
\operatorname{Pr}=0.1881\end{array}$ & $\begin{array}{c}t=-0.6888 \\
\operatorname{Pr}=0.2504\end{array}$ & $\begin{array}{r}t=2.6572 \\
\operatorname{Pr}=0.9914\end{array}$ & $\begin{array}{c}t=2.0364 \\
\text { Pr }=0.9707\end{array}$ \\
\hline
\end{tabular}

Confidence level:

$<90 \%$

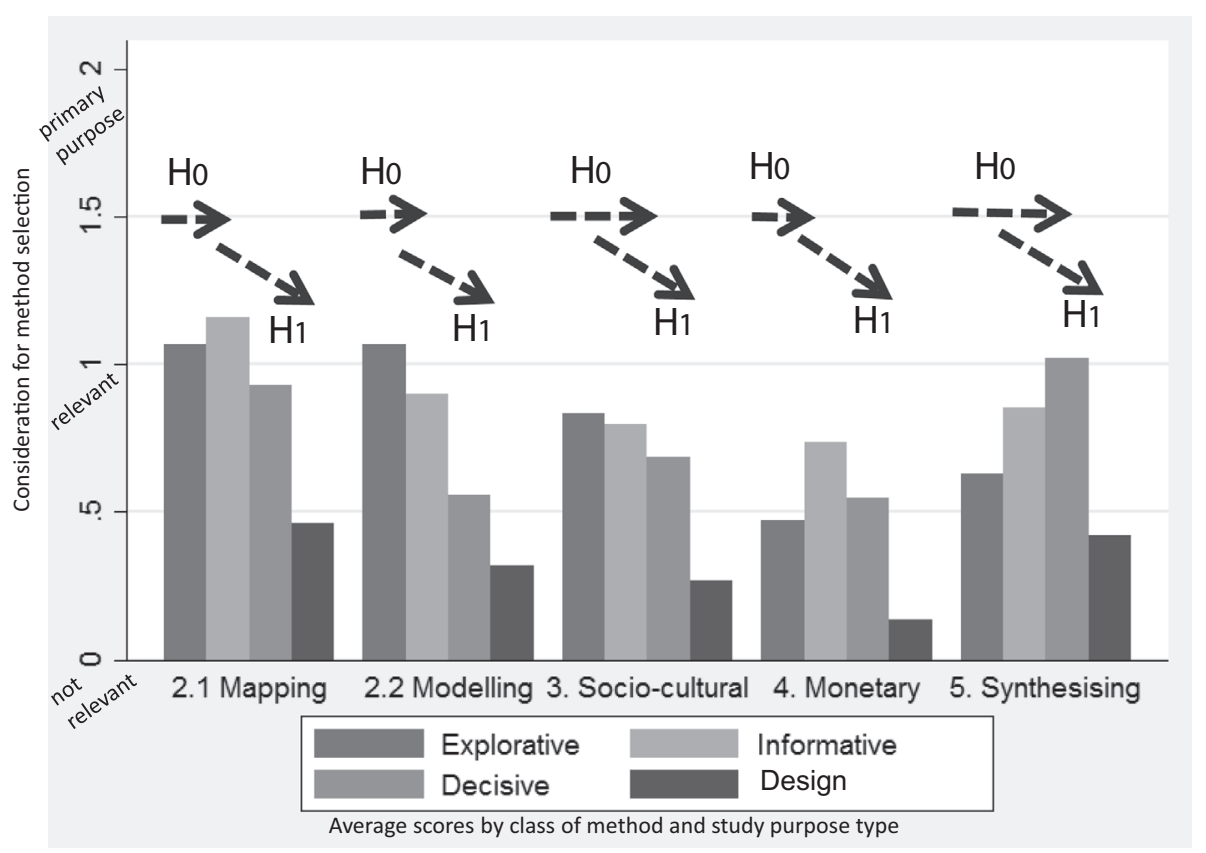

Fig. 4. Mean relevance scores of the purposes of 80 methods from 26 case study leader respondents.

\section{Results}

\subsection{Uses of methods for different purposes}

Fig. 4 shows the mean relevance scores for each of the 5 method classes (defined in Table 2) and for each of the four groups of study purposes (defined in Table 1). Our hypothesis that the applicability of appraisal methods is negatively correlated with an ordering of study purposes by increasing information requirements was moderately supported by the case study leader survey responses. Although we did not test it statistically, visual inspection of Fig. 4 also shows an ordering of method types as expected by the theory of cumulative uncertainty. The detailed distributions of relevance scores are given in Fig. S1, Supplementary material. Comparing methods for the same purpose, we see that 'mapping' methods scored almost as highly as 'synthesising' methods for decisive purposes. Synthesing methods scored the highest for decisive context and in the median range for other purposes. Mapping scored more highly than other individual methods across all purposes, and monetary methods scored the lowest across all purposes (Fig. S1).
A closer inspection of the distributions using the t-test shows that most of the adjacent purposes are different by order of increasing study requirements and expected uncertainty (Table 3 ). There are some exceptions. For example, in the case of modelling methods we are only $83 \%$ confident that decisive purpose is more prevalent than technical design; for socio-cultural methods we are only $79 \%$ confident that informative purposes are more prevalent than decisive purposes. However, Table 3 shows that there is a significant ordering of methods' appropriateness across purposes with increasing requirements. The mean scores by purpose class in Fig. 5 hide a lot of heterogeneity within each class. Fig. S1 in Supplementary materials provides further detail across the 19 different detailed study purposes. From this more detailed picture we see that among explorative study purposes methods development $\mathcal{E}$ design was the most important study purpose for case studies. Among informative purposes creating awareness of the current state and importance of ecosystem services were the dominant purposes across the different case studies. Decisive purposes had no dominant detailed purpose. Decision-support tools (MCDA, $\mathrm{BCA}$ ) and integrated mapping-modelling methods were on the whole more relevant for decisive purposes than were mapping, 


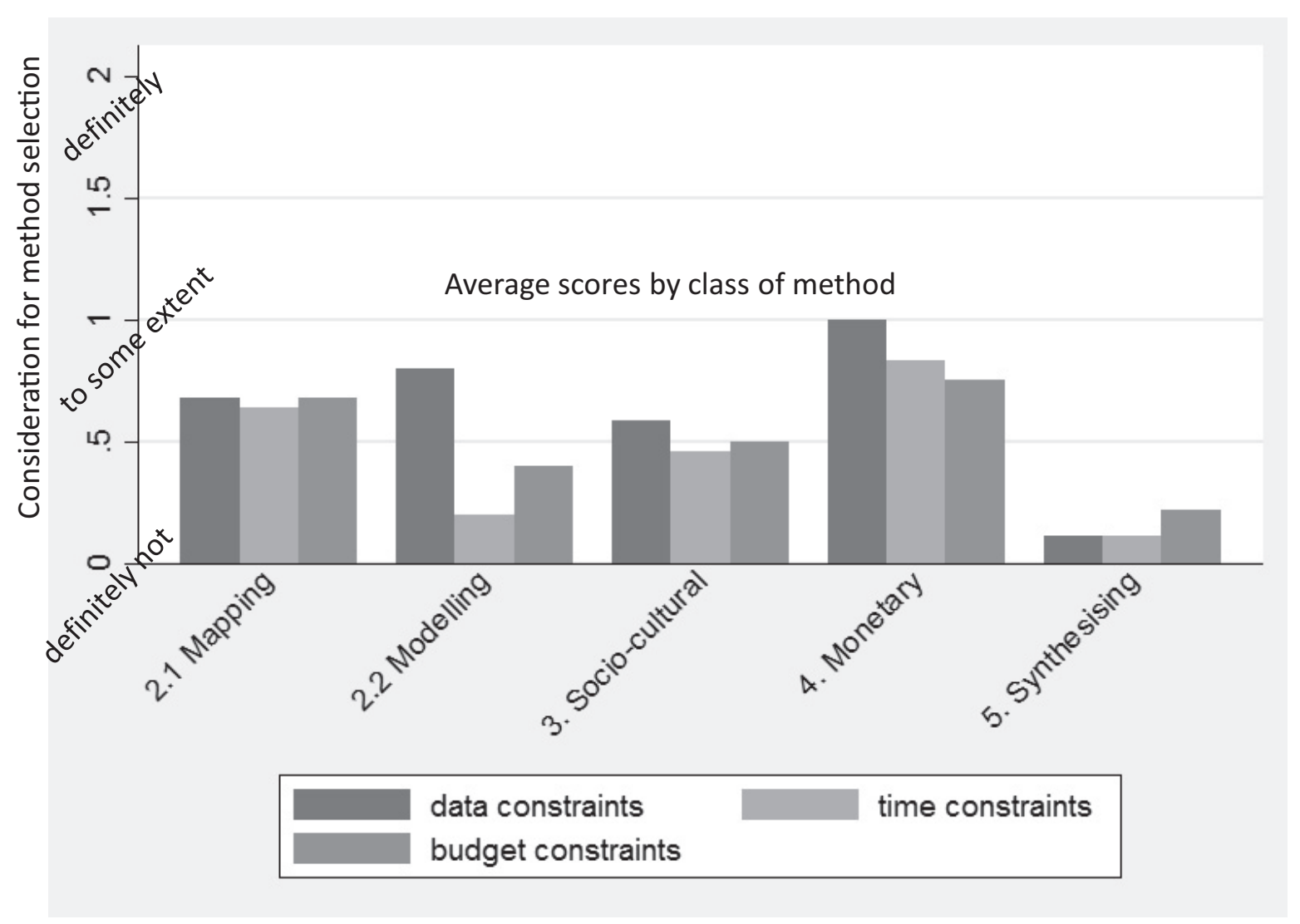

Fig. 5. The importance of constraints in choice of methods relative to their alternatives reported by case study leaders.

modelling and valuation methods on their own. For technical design purposes, input to design of natural resource management rules and regulations was the most relevant technical design purpose across OpenNESS case studies, scoring as high as decisive purposes for both mapping methods and synthesis methods.

Fig. 5 illustrates the relative importance - as assessed by case study leaders - of data, time and budget constraints in the selection of methods used in the case studies. Data constraints within the project are more important in relative terms than time and budget constraints for 'modelling', and to some extent for 'monetary valuation'. But more striking is the fact that the mean importance of data, time and budget constraints in method selection is low, varying from 'to some extent' to 'definitely not'. In other words, none of these constraints - as judged by case study leaders - were 'definitely' important in selecting the methods they used in case studies. We also looked at whether stakeholder-researcher familiarity increased the likelihood of decisive and technical design purposes of studies, using as a proxy the number of years they had worked with stakeholders before initiating OpenNESS. There was no visible effect for any of the study purposes (the results are shown in Supplementary Material, Fig. S2).

\subsection{Participation in appraisal method selection}

In this section, we further question information costs as an underlying mechanism for the information gap between ES appraisal and governance application, using responses to the stakeholder survey. Slightly fewer than half of the stakeholders interviewed "make decisions" about the ecosystem services investigated, while over half "contribute to decision-making"; the majority of stakeholders were "affected" by or "interested" in the ecosystem services issues assessed in the case studies (Fig. S3). A majority of stakeholders found that appraisal methods lead to a "change in future vision in the area", "change in the way information and tools are used to support decisions", "change in decision-making" and "change in actions" (Fig. S4). The stakeholder survey shows that the type and degree of governance support of ES appraisal methods depends on the level of interaction with researchers in the case study advisory board. Fig. 6 shows that stakeholders' advisory role is weakly correlated with some, but not all, types of science-policy interaction. For example, stakeholder participation in study design, knowledge co-production and recipient of information increased signficantly for stakeholders who were members of the advisory board (very applicable), versus those who were not (not applicable). This was not the case for method selection.

\section{Discussion}

\subsection{Uses of methods for different purposes}

To investigate the gap between ES appraisal research and its operational use, we analysed a large set of case study experiences. With the aim to explore the reasons behind the choice of different appraisal methods and their purposes, we formulated an information gap hypothesis predicting an ordering of methods that would be expected in the presence of increasing cumulative uncertainty and method requirements (Fig. 2). We observe some significant ordering effects of methods across study purposes - in particular the difference between decisive and technical design purposes, and to a lesser extent the difference between informative and decisive purposes are apparent (Fig. 3). Individual methods for informative purposes from different parts of the ES appraisal cascade are predominant. Synthesising methods that focus on valuation end-points are less frequent. This could also be explained by the 


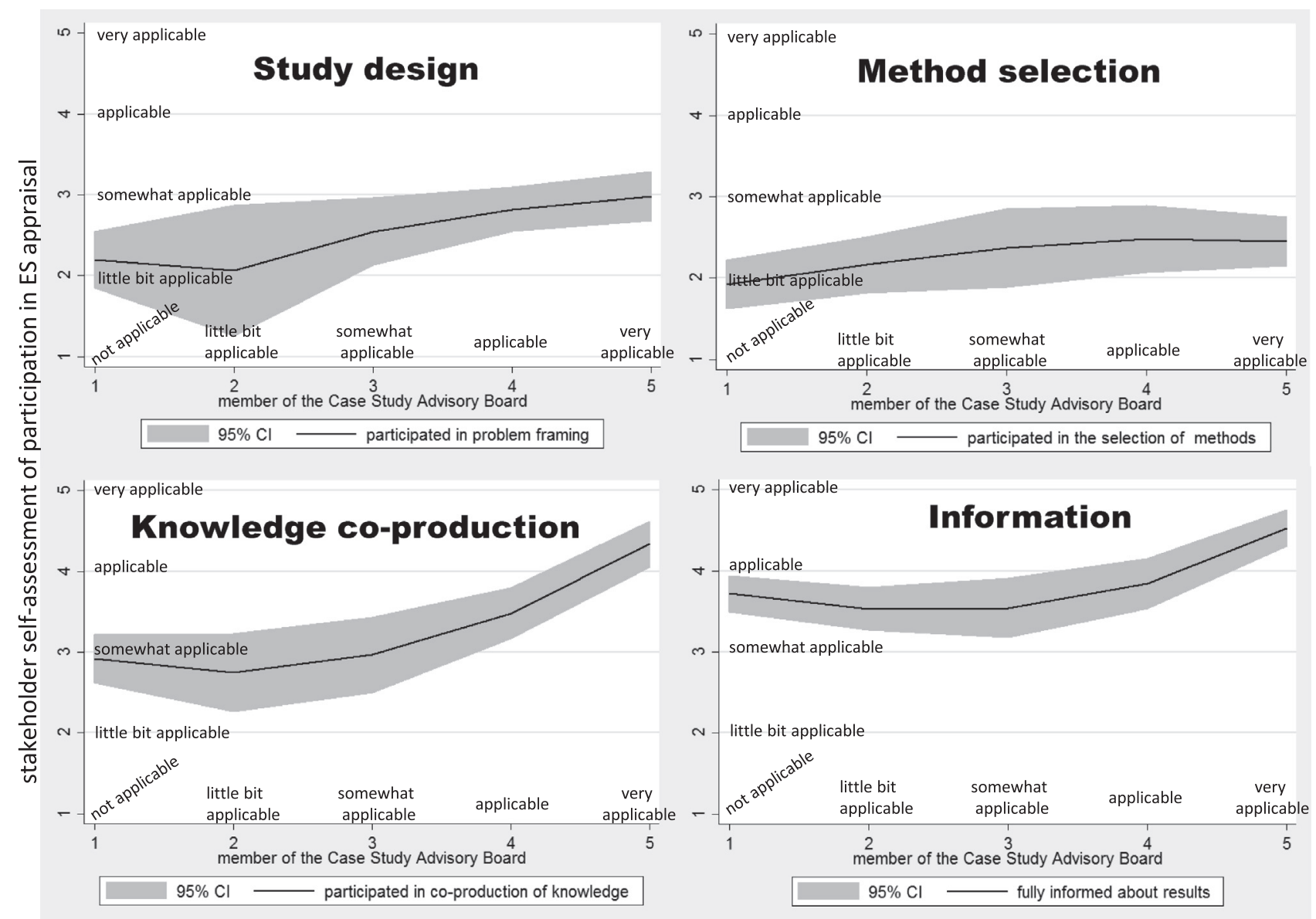

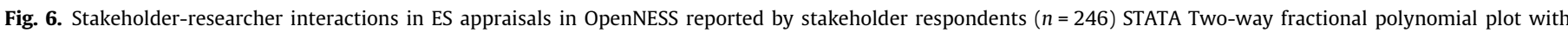
confidence interval (95\%).

novelty of ES appraisals for decision support (Ruckelshaus et al., 2015).

Contrary to the expectation that limited use of appraisals for decisive and technical design purposes is due to constraints on information, we find that on average data, time and budget constraints were not perceived as strong constraints by case study coordinators (Fig. 5). The lack of importance of these factors could be due to explorative and informative purposes being more important than decisive and technical design purposes in a research oriented project like OpenNESS. An additional explanation may be that as a research project, methods were relatively well-resourced, compared to what they would be in e.g. a consultancy. Also, in several case studies that had longer term engagements with their case study sites there were opportunities to combine several financing sources, as well as having access to established data bases. Regarding whether stakeholder-researcher familiarity increased the likelihood of more challenging and more costly purposes of ES appraisal, we find no clear correlation between the importance of decisive or technical design study purposes, and the number of years researchers have worked with stakeholders before the OpenNESS case study started (Fig. S2).

\subsection{Co-design of purpose and method selection by stakeholders}

The stakeholder survey results complemented that of the case study leader survey. The OpenNESS project was operational in the sense of having active participation of stakeholders who are also decision-makers. We looked closer at the type of engagement and the way in which stakeholders interacted with the project. About half the stakeholders did not participate in the problem framing of the project, and slightly more than half did not participate in selecting the assessment methods (summing 'not applicable' and 'slightly applicable' responses). Stakeholder participation in scoping and selection of methods was generally low. This could be explained by the novelty of the project in a large proportion of the cases. In cases with established relationships before OpenNESS, scoping and method selection happened more often. On average the OpenNESS case studies scored higher in terms of coproduction of knowledge, and in providing information inputs to case study advisory boards - what Primmer et al. (2015) called 'governance support', rather than explicit decision support.

Despite case study leaders perception of the decision-support role of their "synthesis" methods, there are indications that the decision-making role of these methods was potential, rather than actual (Figs. S3, S4). As also reported in Dick et al. (2018), only a bit more than $20 \%$ of stakeholders thought that OpenNESS assessment methods had already resulted in "a change in decision making" in the case study site. A further $40 \%$ thought that such a change was likely to take place, while the remainder did not assume such influence. The divergence between researchers' and stakeholders' perceptions of the decision-making role of appraisal methods can partly be traced back to the engagement processes that took place in the case studies. It highlights that involving the 'right' stakeholders (in terms of having decision-making power) is crucial to realize real decision-support. The question of which stakeholders to interact with to increase impact is 
complicated by hierarchical governance (Primmer et al., 2015). Still, our assessment is somewhat more optimistic than findings from the Natural Capital project (Ruckelshaus et al., 2015) where a 3-4 year research project was deemed insufficient to observe operational changes in decision-making.

The question remains whether the expectation of change in decision-making procedure can be interpreted as an actual sign of operationalisation. Based on stakeholder survey results, the OpenNESS project was relatively successful in achieving decisionmaker participation in the CABs (Fig. S3). However, case studies were on the whole less effective in engaging them in study design and methods selection than in knowledge co-production and keeping them informed (Fig. 6). Laurans and Mermet (2014) point out that studies for informative purposes can have a decisive effect over time as they can help reframe the policy debate. Ruckelshaus et al. (2015) argue that case study purposes evolve over the longer term as dynamic 'impact pathways'.

\subsection{ES appraisal methods as value articulating institutions}

Valuation methods range from biophysical, monetary, social to integrative/synthesizing methods. ES appraisal methods all produce information about ES 'importances', or what GómezBaggethun et al. (2014) call plural values of ES. Environmental appraisal methods in this broad sense are value articulating institutions (Vatn, 2005, 2009). Jacobs et al. (2016) evaluate application of 21 different valuation methods in various real-life case studies. They argue that the methods generate values rather than measuring them as an external objects. Every method articulates different values. Methods should be carefully selected and combined to obtain a valid, just and credible decisions (Jacobs et al., 2016). In this paper, we take this argument further by identifying the variation in institutional (decision) contexts that a given appraisal method may be designed for.

The OpenNESS experience reveals that monetary valuation was applied in a small minority of case studies. Furthermore, where monetary valuation methods were applied, they were mainly conducted for informative purposes, in particular 'awareness-raising on the importance of ecosystem services' (Fig. S1). This finding could be taken to confirm the decision-support gap in monetary valuation found in the review by Laurans et al. (2013), but we have admittedly a very small sample. It may also be a result of the classification of individual monetary valuation methods and benefit-cost analysis into separate categories. The majority of monetary valuation methods found in the academic literature by Laurans et al. (2013) may be monetary valuation methods observed out of their potential decision-support role in applied benefit-cost analysis. Indeed, the formal documentation of the information value of monetary valuation for decision-making is demanding (Barton, 2007).

Looking at detailed purposes it is also interesting to note that mapping is perceived to be conducted, as we would expect, for informative purposes ('current state', 'awareness of ES importance'), but also for decisive purposes at a similar level of importance as 'synthesising' methods (lower left hand panel Fig. S1). Within the group of decisive purposes, mapping methods were predominantly conducted for 'spatial targeting', but notably also as 'arguments for negotiation, shared norms $\mathcal{E}$ ' conflict reduction'. This provides support for the assertion that mapping can also be a tool for framing and articulating values (Hauck et al., 2013; MartínLópez et al., 2014). This was particularly true in OpenNESS where a number of participatory mapping methods were tested.

\subsection{Information requirements of appraisal methods}

While we found a significant ordering of methods across purposes with increasing requirements we could not explain the ordering using information costs. The constraints of data availability, information and resources are expected to be the strongest for novel decision-support problems. OpenNESS case studies often applied novel methods for their study sites (Dunford et al., 2018), with explorative purposes being among the most important for mapping, modelling, and socio-cultural methods. Here, there may be a selection bias from the point of view of decision-makers in the case study advisory boards. Novel studies need to be explorative until their reliability is tried and tested. While methods are being tested they may also be informative, to the extent that engagement with stakeholders is actively pursued. While OpenNESS was designed to promote co-production of knowledge, it seems reasonable to assume that cautious decision-makers will be less likely to use novel methods for decisive and technical design purposes, despite researchers' perception of their methods' potential. Fig. 1 suggests that ES appraisal methods - and integrated valuation more widely (Jacobs et al. 2016) - must be perceived as reliable before being used by decision-makers to prioritise between alternative actions. Ecosystem services appraisal requires tailor-made forms and modes of societal involvement. These also require new qualities of public policies and new roles of governments (Verburg et al., 2016). These new roles include deliberative processes at various governance levels (Primmer et al., 2015) and new types of contracts, ample resources, sufficient knowledge on ES and long term commitment (Verburg et al., 2016). Our contention is that OpenNESS' success as a research project in applying novel knowledge co-production methods with stakeholders, to some extent 'self-selected' away from decisive and technical design purposes. The exception may be the handful of 'synthesis' methods, including for example multi-criteria decision analysis (MCDA). Some individual cases also actively pursued decisive and technical design purposes, e.g. (Barton et al., 2015; Dick et al., 2017; Peri et al., 2017).

\subsection{Uncertainty and (dis)integrated valuation}

While it is true that integrated environmental impact modelling can lead to large cumulative uncertainty (Barton et al., 2016), the DPSIR approach and cost-benefit analysis are particular interpretations of integrated valuation which rely on conditionally dependent modelling (Fig. 7). In other words, they are types of integrated valuation particularly prone to cumulative uncertainty. Multi-criteria decision analysis tries to mitigate this by considering biophysical, social and economic criteria separately, but may not escape uncertainty accumulation if criteria are causally related (as shown in Fig. 7), or if they are scaled to a common unit of comparison (Saarikoski et al., 2016). Method triangulation takes a different approach, treating mapping, biophysical modelling, sociocultural asseessment and monetary valuation as independent plural value inputs to decision-making (Jacobs et al., 2016). Method triangulation cannot avoid correlated errors altogether, but it is suggested that consideration of independent impact criteria with no formal method of comparison can increase reliability of decisions (Jacobs et al., 2016).

A comparison of costs and benefits of actions- whether quantitative or qualitative - requires some kind of mapping-modellingvaluation synthesis procedure (IPBES, 2015). As we increasingly integrate parallel ES appraisal methods with the aim of decision support, we should expect stochastic events to combine and generate - explicitly or implicitly - a joint probability distribution of predicted policy outcomes. Decision-makers potentially make decision errors because of this probability distribution of outcomes. Knowing this, rational decision-makers will balance the information costs of more ES appraisals against the information value of avoiding "costly actions" (Type I) or "missed opportunities" (Type II) (see Supplementary Material S1). If 


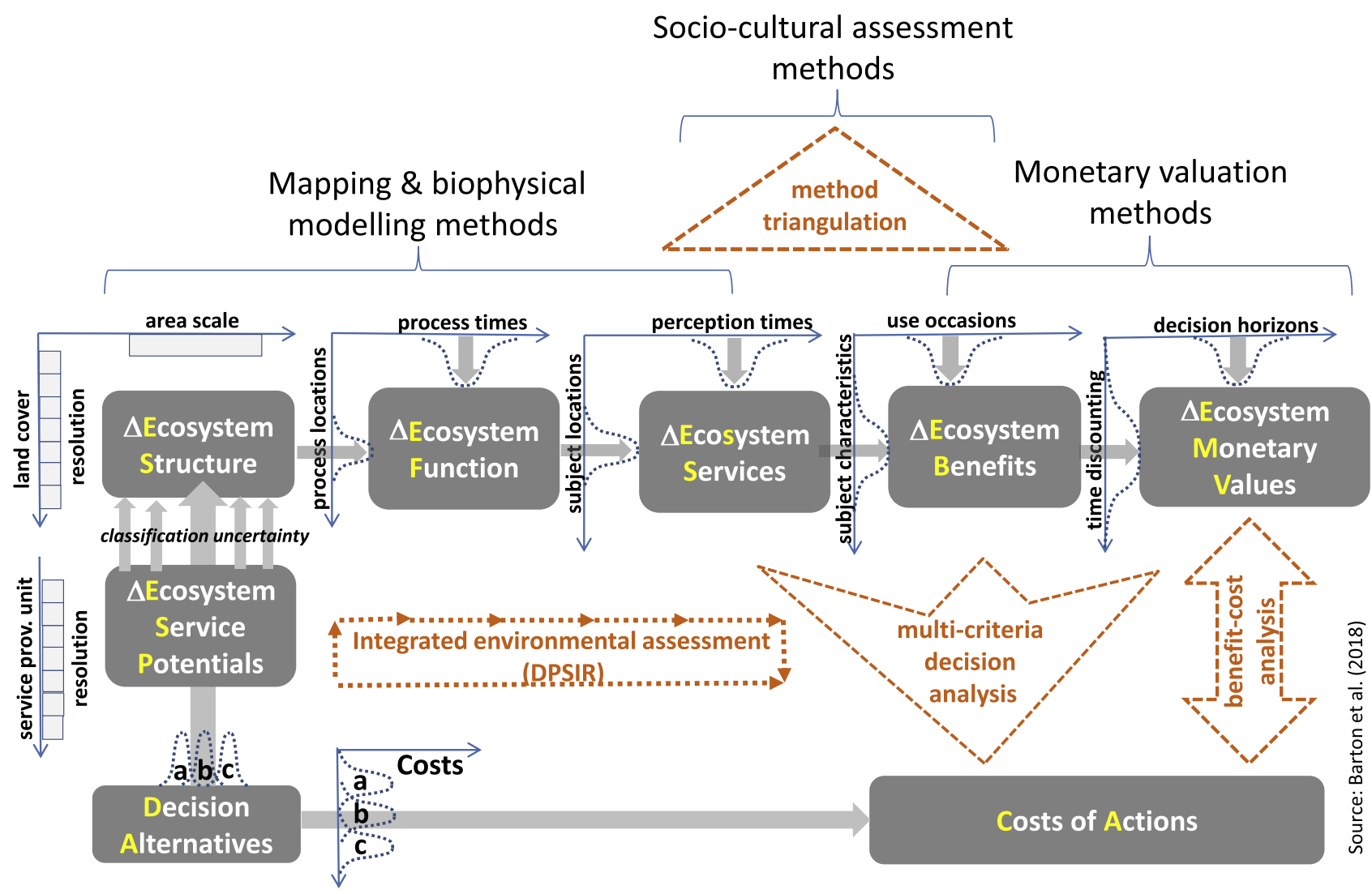

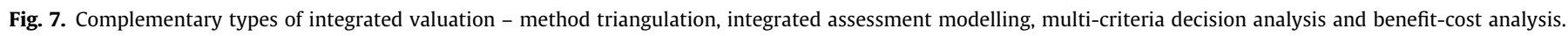

decision-makers avoid designing one-shot decisions - and consultants avoid offering single-answer ES appraisals - then adaptive management, combined with method triangulation, iteration and updating of appraisals, offers a way to close the information gap.

\section{Conclusions}

We developed a theory of cumulative uncertainty in integrated ES apprisal based on a 'stairway' framework of ES appraisal. Successive ES appraisals - from mapping, modelling to benefit assessment and valuation - lead stakeholders to expect higher cumulative uncertainty in outcomes. Given an expectation about uncertainty, the more demanding the decision-support purpose of the ES appraisal, the lower the likelihood that the ES appraisal will be considered appropriate for decision-support. We defined an information gap hypothesis based on particular governance requirements for accuracy and reliability, combined with increasing uncertainty of the ES appraisal methods' outcomes. In order to test the information gap hypothesis, we evaluated responses to survey data of case study coordinators and stakeholders from 26 case studies and 80 ecosystem services appraisals in a large integrated EU research project. We classified different ES appraisal methods in terms of their purpose - explorative, informative, decisive and design. We grouped ES appraisal methods into types mapping, modelling, socio-cultural assessment, monetary valuation and synthesizing methods. We tested the likelihood of ES method types being appropriate for different purposes, as evaluated by the researchers who used them. We found some support for decreasing likelihood of ES appraisal methods with increasing governance requirements for accuracy and reliability. We discussed whether the likelihood of different method-purpose combinations was conditional on our theoretical expectations about uncertainty of outcomes. We do not find support for resource or time availability as an explanation for information gaps. Instead, stakeholder surveys show that decreasing appropriateness of ES appraisal methods for decisive and design purposes could be due to the research project interacting mostly with stakeholders outside the most decision-relevant contexts. Finally, we discussed how our theory of cumulative uncertainty in ES appraisal is based on a particular understanding of integrated valuation. The cumulative uncertainty and information gaps we uncovered may be particularly relevant for integrated impact assessment and benefit-cost analysis, while being less so for multi-criteria analysis and method triangulation. This leads us to suggest combining strategies for addressing information gaps. Despite the empirical limitations of our study, we conclude that more systematic consideration of uncertainty and information costs in ES appraisal, together with the active pursuit of knowledge co-production with stakeholders, will contribute to narrowing the operational gap in ES appraisal, moving in the direction of integrated valuation.

\section{Acknowledgements}

This research was funded by the European Union EU FP7 project OpenNESS (Grant agreement no. 308428). MGL was fund by a grant from the Spanish National Institute for Agriculture and Food Research and Technology (INIA), which is co-funded by the Social European Fund.

\section{Appendix A. Supplementary data}

Supplementary data associated with this article can be found, in the online version, at https://doi.org/10.1016/j.ecoser.2017.10.021. 


\section{References}

Bagstad, K.J., Semmens, D.J., Waage, S., Winthrop, R., 2013. A comparative assessment of decision-support tools for ecosystem services quantification and valuation. Ecosyst. Serv. 5, E27-E39.

Barton, D.N., 2007. How much is enough? The value information from benefit transfers in a policy context. In: Navrud, S., Ready, R. (Eds.), Environmental Value Transfer: Issues and Methods. Springer, Dordrecht, pp. 261-282.

Barton, D.N., Andersen, T., Bergland, O., Engebretsen, A., Moe, S.J., Orderud, G.I., Tominaga, K., Romstad, E., Vogt, R.D., 2016. Eutropia: integrated valuation of lake eutrophication abatement decisions using a bayesian belief network. In: Chap.14 in Niel, Z. P. (Ed.) Handbook of Applied Systems Science. Routledge, New York and London, pp. 297-320. https://doi.org/10.4324/9781315748771. ch14.

Barton, D.N., Saloranta, T., Moe, S.J., Eggestad, H.O., Kuikka, S., 2008. Bayesian belief networks as a meta-modelling tool in integrated river basin management Pros and cons in evaluating nutrient abatement decisions under uncertainty in a Norwegian river basin. Ecol. Econ. 66, 91-104.

Barton, D.N., Stange, E., Blumentrath, S., Traaholt, N.V., 2015. Economic valuation of ecosystem services for policy. A pilot study on green infrastructure in Oslo [NINA Report 1114, 77p]. http://www.openness-project.eu/node/78.

Dick, J., Verweij, P., Carmen, E., Rodela, R., Andrews, C., 2017. Testing the ecosystemservice cascade framework and QUICKScan software tool in the context of landuse planning in Glenlivet Estate Scotland. Int. J. Biodivers. Sci. Ecosyst. Serv. Manage. 13, 12-25. https://doi.org/10.1080/ 21513732.2016.1268648.

Dick, J. et al., 2018. Stakeholders' perspectives on the operationalisation of the ecosystem service concept: results from 27 case studies. Ecosyst. Serv. 29, 552565. https://doi.org/10.1016/j.ecoser.2017.09.015.

Dunford, R. et al., 2018. Integrating methods for ecosystem service assessment: experiences from real world situations. Ecosyst. Serv. 29, 499-514. https://doi. org/10.1016/j.ecoser.2017.10.014.

Fagerland, M.W., Sandvik, L., Mowinckel, P., 2011. Parametric methods outperformed non-parametric methods in comparisons of discrete numerical variables. BMC Med. Res. Methodol. 11.

Fontaine, C.M., Dendoncker, N., De Vreese, R., Jacquemin, I., Marek, A., Van Herzele, A., Devillet, G., Mortelmans, D., François, L., 2014. Towards participatory integrated valuation and modelling of ecosystem services under land-use change. J. Land Use Sci. 9, 278-303.

Gomez-Baggethun, E., Barton, D.N., 2013. Classifying and valuing ecosystem services for urban planning. Ecol. Econ. 86, 235-245.

Gómez-Baggethun, E., Martín-López, B., Barton, D.N., Braat, L., Saarikoski, H. Kelemen, E., García-Llorente, M., van den Burgh, J., Arias, P., Berry, P., Potschin, M., Keene, H., Dunford, R., Schröter-Schlaack, C., Harrison, P., 2014. EU FP7 OpenNESS Project Deliverable 4.1. State-of-the-art report on integrated valuation of ecosystem services. European Commission FP7.

Grêt-Regamey, A., Altwegg, J., Sirén, E.A., van Strien, M.J., Weibel, B., 2016 Integrating ecosystem services into spatial planning-A spatial decision support tool (online version) Landscape Urban Plann.

Haines-Young, R., Potschin, M., 2010. The links between biodiversity, ecosystem services and human well-being'. In: Raffaelli, D., Frid, C. (Eds.), Ecosystem Ecology: a new synthesis. Cambridge University Press, Cambridge, pp. 110-139.

Harrison, P.A. et al., 2018. Selecting methods for ecosystem service assessment: A decision tree approach. Ecosyst. Serv. 29, 481-498. https://doi.org/10.1016/j. ecoser.2017.09.016.

Hauck, J., Görg, C., Varjopuro, R., Ratamäki, O., Maes, J., Wittmer, H., Jax, K., 2013. "Maps have an air of authority": Potential benefits and challenges of ecosystem service maps at different levels of decision making. Ecosyst. Serv., 25-32

Hausknost, D., Grima, N. Singh, S.J., 2017. The political dimensions of Payments for Ecosystem Services (PES): Cascade or stairway? Ecol. Econ. 131, 109-118.

IPBES, 2015. Preliminary guide regarding diverse conceptualization of multiple values of nature and its benefits, including biodiversity and ecosystem functions and services (deliverable 3 (d)). Intergovernmental Science-Policy Platform on Biodiversity and Ecosystem Services.

Jacobs, S., Dendoncker, N., Martin-Lopez, B., Barton, D.N., Gomez-Baggethun, E. Boeraeve, F., McGrath, F.L., Vierikkoh, K., Geneletti, D., Sevecke, K.J., Pipart, N., Primmer, E., Mederly, P., Schmidt, S., Aragao, A., Baral, H., Bark, R.H., Briceno, T., Brogna, D., Cabral, P., De Vreese, R., Liquete, C., Mueller, H., Peh, K.S.H., Phelan, A., Rincon, A.R., Rogers, S.H., Turkelboom, F., Van Reeth, W., van Zanten, B.T. Wam, H.K. Washbourne, C.L., 2016. A new valuation school: Integrating diverse values of nature in resource and land use decisions. Ecosyst. Serv. 22, 213-220.
Jacobs, S. et al., 2018. The means determine the end - pursuing integrated valuation in practice. Ecosyst. Serv. 29, 515-528. https://doi.org/10.1016/j. ecoser.2017.07.011.

Laurans, Y., Mermet, L., 2014. Ecosystem services economic valuation, decisionsupport system or advocacy? Ecosyst. Serv. 7, 98-105.

Laurans, Y., Rankovic, A., Billé, R., Pirard, R., Mermet, L., 2013. Use of ecosystem services economic valuation for decision making: Questioning a literature blindspot. J. Environ. Manage. 119, 208-219.

Martin-Lopez, B., Gomez-Baggethun, E., Garcia-Llorente, M., Montes, C., 2014. Trade-offs across value-domains in ecosystem services assessment. Ecol. Indic. 37, 220-228.

Martín-López, B., Gomez-Baggethun, E., García-Llorente, M., Montes, C., 2014. Trade-offs across value-domains in ecosystem services assessment. Ecol. Indic. 37 (2014), 220-228.

Martinez-Harms, M.J., Bryan, B.A., Balvanera, P., Law, E.A., Rhodes, J.R., Possingham, H.P., Wilson, K.A., 2015. Making decisions for managing ecosystem services. Biol. Conserv. 184, 229-238.

Nassl, M., Loffler, J., 2015. Ecosystem services in coupled social-ecological systems: Closing the cycle of service provision and societal feedback. Ambio 44, 737-749.

Pascual, U.E.A.C.-A., 2017. Valuing nature's contributions to people: the IPBES approach. Curr. Opin. Environ. Sustainability. https://doi.org/10.1016/ j.cosust.2016.12.006 26-27, 7-16.

Peri, P., López, D., Rusch, V.E., Rusch, G.M., Martínez-Pastur, G., 2017. State and transition model approach in native forests of Southern Patagonia: Linking ecosystem services, thresholds and resilience. Int. J. Biodivers. Sci. Ecosyst. Serv. Manage., 105-118

Potschin, M., Haines-Young, R., 2016. Defining and measuring ecosystem services. In: Potschin, M., Haines-Young, R., Fish, R., Turner, R.K. (Eds.), Routledge Handbook of Ecosystem Services. Routledge, p. 640.

Primmer, E., Jokinen, P., Blicharska, M., Barton, D.N., Bugter, R., Potschin, M., 2015 Governance of ecosystem services: a framework for empirical analysis. Ecosyst. Serv. 16, 158-166. https://doi.org/10.1016/j.ecoser.2015.05.002i.

Rasch, D., Teuscher, F., Guiard, V., 2007. How robust are tests for two independent samples? J. Stat. Plan. Infer. 137, 2706-2720.

Ruckelshaus, M., McKenzie, E., Tallis, H., Guerry, A., Daily, G., Kareiva, P., Polasky, S., Ricketts, T., Bhagabati, N., Wood, S.A., Bernhardt, J., 2015. Notes from the field: Lessons learned from using ecosystem service approaches to inform real-world decisions. Ecol. Econ. 115, 11-21.

Saarikoski, H., Mustajoki, J., Barton, D.N., Geneletti, D., Langemeyer, J., GomezBaggethun, E., Marttunen, M., Antunes, P., Keune, H., Santos, R., 2016. Multicriteria decision analysis and cost-benefit analysis: comparing alternative frameworks for integrated valuation of ecosystem services. Ecosyst. Serv. 22, 238-249.

Schröter, M., Barton, D.N., Remme, R.P., Hein, L., 2014. Accounting for capacity and flow of ecosystem services: a conceptual model and a case study for Telemark, Norway. Ecol. Indic. 36, 539-551.

Spangenberg, J.H., von Haaren, C., Settele, J., 2014. The ecosystem service cascade: Further developing the metaphor. Integrating societal processes to accommodate social processes and planning, and the case of bioenergy. Ecol. Econ. 104, 22-32.

Stata, 2013. Stata graphics reference manual. Release 13. https://www. stata.com/manuals13/g.pdf Stata Press Publication, StataCorp LP, College Station, Texas.

TEEB, 2010. The Economics of Ecosystems and biodiversity: mainstreaming the economics of nature: a synthesis of the approach, conclusions and recommendations of TEEB. TEEB Ocotber 2010.

van Oudenhoven, A.P.E., Siahainenia, A.J., Sualia, I., Tonneijck, F.H., van der Ploeg, S., de Groot, R.S., Alkemade, R., Leemans, R., 2015. Effects of different management regimes on mangrove ecosystem services in Java, Indonesia. Ocean Coast. Manage. 116, 353-367.

Vatn, A., 2005. Institutions and the environment. Edward Elgar Pub., Cheltenham, UK; Northampton, MA.

Vatn, A., 2009. An institutional analysis of methods for environmental appraisal. Ecol. Econ. 68, 2207-2215.

Verburg, R., Selnes, T., Verweij, P., 2016. Governing ecosystem services: National and local lessons from policy appraisal and implementation. Ecosyst. Serv. 18, 186-197.

Yee, S.H., Carriger, J.F., Bradley, P., Fisher, W.S., Dyson, B., 2015. Developing scientific information to support decisions for sustainable coral reef ecosystem services. Ecol. Econ. 115, 39-50. 